8 - ORIGINAL ARTICLE

ISCHEMIA-REPERFUSION

\title{
Ozone oxidative preconditioning protects the rat kidney from reperfusion injury via modulation of the TLR4-NF-KB pathway ${ }^{1}$
}

\author{
Bianzhi Xing', Hui Chen ${ }^{\mathrm{II}}$, Lei Wang ${ }^{\mathrm{III}}$, Xiaodong Weng ${ }^{\mathrm{III}}$, Zhiyuan Chen ${ }^{\mathrm{III}}$, Xiuheng Li ${ }^{\mathrm{IV}}$ \\ DOI: http://dx.doi.org/10.1590/S0102-86502015001000008
}

IPhD, Physician, Department of Department of Radiology, Renmin Hospital, Wuhan University, Hubei, China. Conception and design of the study, acquisition and analysis of data, manuscript writing

IIPhD, Physician, Department of Urology, Renmin Hospital, Wuhan University, Hubei, China. Design of the study, supervised all phases of the study, critical revision.

IIIPhD, Physician, Department of Urology, Renmin Hospital, Wuhan University, Hubei, China. Acquisition of data.

${ }^{\text {IV }} \mathrm{PhD}$, Full Professor, Department of Urology, Renmin Hospital, Wuhan University, Hubei, China. Design of the study, acquisition of data, critical revision.

\begin{abstract}
PURPOSE: To investigate the protective effects of ozone oxidative preconditioning (OzoneOP) were associated with the modulation of TLR4-NF-KB pathway.

METHODS: Thirty six rats were subjected to $45 \mathrm{~min}$ of renal ischemia, with or without treatment with OzoneOP (1 mg/kg). Blood samples were collected for the detection of blood urea nitrogen and creatinine levels. Histologic examinations were evaluated and immunohistochemistry was also performed for localization of TLR 4 and NF- $\kappa B$. The expression of TNF- $\alpha$, IL- $1 \beta$, IL-6, ICAM- 1 and MCP-1 were studied by Real-time PCR. Western blot was performed to detect the expression of TLR4 and NF-KB.

RESULTS: The results indicated that blood urea nitrogen and creatinine levels increased significantly in I/R group. Rats treated with OzoneOP showed obviously less renal damage. Immunohistochemistry showed that TLR4 were ameliorated by OzoneOP. Realtime PCR showed that OzoneOP could significantly inhibit the increased mRNA levels of TNF- $\alpha$, IL-1 $\beta$, IL-6, ICAM- 1 and MCP-1 induced by $\mathrm{I} / \mathrm{R}$. Western blot indicated that the expression of TLR 4 and NF- $\mathrm{kB}$ were upregulated in $\mathrm{I} / \mathrm{R}$ group, but OzoneOP could inhibit this increase.
\end{abstract}

CONCLUSION: These findings indicated that OzoneOP had potent anti-inflammatory properties by the modulation of the TLR4-NF$\kappa \mathrm{B}$ pathway in renal ischemia/reperfusion injury.

Key words: Ozone. Ischemia. Reperfusion. Toll-Like Receptor 4. NF-kappa B. Kidney. Rats. 


\section{Introduction}

Ischemia/reperfusion ( $\mathrm{I} / \mathrm{R})$ injury, which is commonly seen in the field of renal surgery or transplantation, is a major cause of acute renal failure (ARF). Although reperfusion is essential for the survival of ischemic tissue, there is good evidence that reperfusion itself causes additional cellular injury. The pathophysiology of ischemic ARF is very complex but ultimately results from tubular destruction, obstructive cast formation, and widespread vascular damage. Studies demonstrated that inflammatory response emerged as a primary and major contributor to the pathophysiology of renal $\mathrm{I} / \mathrm{R}$ and determined the outcome of renal damage. Toll-like receptors 4 (TLR4) is a transmembrane protein that plays a central role in inflammatory cascade after renal I/R injury ${ }^{1}$. Renal ischemia/reperfusion injury up-regulate TLR4 and the activation of TLR4 result in the release of NF- $\kappa B$ from I $\kappa$ B. NF- $\kappa \mathrm{B}$ mediates the increase in inflammatory cytokine gene expression. Increasing experimental studies indicated that the TLR4-NF- $\kappa \mathrm{B}$ pathway might trigger inflammation and might be closely correlated with renal I/R injury ${ }^{2}$.

Ozone $\left(\mathrm{O}_{3}\right)$ has been used as a therapeutical agent for the treatment of different diseases ${ }^{3}$. It has been demonstrated that ozone oxidative preconditioning (OzoneOP) induced protective effects in renal I/R injury ${ }^{4-7}$. It is a simple and harmless method which provides a new tool to protect organ from $I / R$ injury. Our previous studies has demonstrated that OzoneOP reduced inflammatory responses in rat renal $\mathrm{I} / \mathrm{R} \operatorname{model}^{5}$. However, it remained to be determined whether the renoprotective effect of OzoneOP was associated with modulation of the TLR4- NF- $\mathrm{BB}$ pathway. The major purposes of this study were to determine whether OzoneOP attenuated the inflammatory response by the modulation of the TLR4-NF- $\kappa$ B pathway in renal I/R injury.

\section{Methods}

\section{Animal preparation and experimental design}

This project was approved by the committee of experimental animals of Wuhan University, and the procedures were carried out according to the routine animal-care guidelines. All experimental procedures complied with the Guide for the Care and Use of Laboratory Animals.

Thirty six adult male Wistar rats (250-280g, SPF grade) were supplied by the Center of Experimental Animals in Medical College, Wuhan University. Animal preparation was performed as previously described ${ }^{5-7}$. Briefly, adult male Wistar rats were anesthetized with pentobarbital intraperitoneally $(45 \mathrm{mg} / \mathrm{kg})$ and allowed to breathe room air spontaneously. After $500 \mathrm{U}$ of heparin (intraperitoneally), a 10-min stabilization period and maintaining the body temperature at $37^{\circ} \mathrm{C}$, a midline laparotomy was performed. A right nephrectomy was performed, and the left renal artery and vein were isolated; 30 min with no further surgical intervention was allowed for circulatory re-adjustment after right nephrectomy. The left kidney was subjected to $45 \mathrm{~min}$ of ischemia followed by reperfusion after right nephrectomy.

All animals were randomly separated into three different group respectively, based on randomized block design. Group 1. sham-operated control (sham, $n=12$ ): rats were subjected to anaesthesia and laparatomy plus surgical manipulation, without the induction of renal ischaemia. Group 2. ischemia/reperfusion group $(I / R, n=12)$ : rats were subjected to left renal ischemia for $45 \mathrm{~min}$ followed by reperfusion. Group 3. ozone oxidative preconditioning group (OzoneOP $+\mathrm{I} / \mathrm{R}, \mathrm{n}=12)$ : Before the $I / R$ procedure (as in group 2), rats were treated with ozone as previously described ${ }^{5-7}$. Briefly, rats received 15 ozone treatments by rectal insufflations $1 \mathrm{mg} \mathrm{kg-1}$, once a day, at an ozone concentration of $50 \mu \mathrm{g} \mathrm{ml}-1$. Rats were killed at $24 \mathrm{~h}$ after I/R injury. Blood samples $(1 \mathrm{~mL})$ were taken from the inferior vena cava for the measurement of urea nitrogen (BUN) and creatinine $(\mathrm{Cr})$.

\section{Preservation of kidneys}

The left kidney was removed under fully maintained anaesthesia. After removal, the kidney was fixed in 10\% phosphatebuffered formalin or immediately frozen, and stored at $-80^{\circ} \mathrm{C}$ for different determinations.

\section{Serum assays}

To assess $\mathrm{Cr}$ and BUN, blood samples ( $\mathrm{n}=6$ for each group) were collected, centrifuged and kept at $-20^{\circ} \mathrm{C}$ until analyses, adopting standard techniques using an Olympus AU 2700 Analyzer (Olympus Optical Co. Ltd, Tokyo, Japan).

\section{Histological examination}

The kidney was fixed in 10\% neutral-buffered formalin, paraffin embedded and sectioned at $4 \mathrm{um}$ thick according to the standard procedure. The sections were deparaffinized and hydrated gradually, and examined by HE staining. Morphological 
assessment was performed by an experienced renal pathologist who was unaware of the treatment. A grading scale of $0-4$, as outlined by Jablonski ${ }^{8}$, was used for the histopathological assessment of ischemia/reperfusion-induced damage of the proximal tubules.

\section{Immunohistochemistry}

The expression of TLR4 and NF- $\mathrm{BB}$ were conducted by immunohistochemical staining. Briefly, 4- $\mu$ m sections were deparaffinized, and endogenous peroxidase activity was blocked with $3 \%$ hydrogen peroxide at $37^{\circ} \mathrm{C}$ for $10 \mathrm{~min}$. Then the sections were treated with $10 \%$ normal goat serum in Tris-buffered saline (TBS) for $30 \mathrm{~min}$ at $37^{\circ} \mathrm{C}$. Subsequently, they were incubated overnight at $4^{\circ} \mathrm{C}$ with anti-TLR4 (Cell Signaling Technology, Boston, MA) and anti-NF- $\mathrm{B}$ (Cell Signaling Technology, Boston, MA). After washing three times with PBS, these sections were incubated with the secondary antibody for $30 \mathrm{~min}$ at room temperature, followed by color reagent DAB. In negative control group, the experiments were routinely performed.

\section{Realtime PCR}

Total RNAwere isolated using Trizol reagent(Invitrogen) and RNA concentration was obtained by spectrophotometer $(n=6$ for each group). Single-stranded cDNA was synthesized using the cDNA synthesis kit (Takara, Kyoto, Japan) according to the procedures. Reverse transcription-polymerase chain reaction (PCR) was performed with the Applied Biosystems SYBR Green mix kit (Applied Biosystems, CA, USA). TNF- $\alpha$ forward primer 5'- GCCACCACGCTCTTCTGTC-3', and TNF- $\alpha$ reverse primer 5' GCTACGGGCTTGTCACTCG- 3' (Gen-Bank accession numberNM_012675.3); The primers used were as follows: IL-1 $\beta$ forward primer 5'-ACTATGGCAACTGTCCCTGAAC-3', and IL-1 $\beta$ reverses primer 5'-GTGCTTGGGTCCTCATCCTG-3' (Gen-Bank accession number NM_031512.2); IL-6 forward primer 5'- TTGCCTTCTTGGGACTGATGT-3', and IL-6 reverses primer 5' - TACTGGTCTGTTGTGGGTGGT-3' (GenBank accession number NM_012589.1); ICAM-1 forward primer 5'- GGGATGGTGAAGTCTGTCAA-3' , and ICAM1 reverses primer 5'- GGCGGTAATAGGTGTAAATGG-3' (Gen-Bank accession number NM_012967); MCP-1 forward primer 5' - CATCAACCCTAAGGACTTCAGC-3', and MCP1 reverses primer 5'- TCTACAGAAGTGCTTGAGGTGGT-3' (Gen-Bank accession number NM_ NM_031530.1);TLR4 forward primer 5'- TATCCAGAGCCGTTGGTGTATCT-3', and TLR4 reverses primer 5'- AATGAAGATGATGCCAGAGCG-3'
(Gen-Bank accession number NM_019178.1). $\beta$-actin forward primer 5'- TGCTATGTTGCCCTAGACTTCG-3' and $\beta$-actin reverses primer 5'- GTTGGCATAGAGGTCTTTACGG-3' (Gen-Bank accession number NM_031144). $\beta$-actin was used as a housekeeping gene. Relative mRNA levels were normalized to those of $\beta$-actin and described as the fold change from the sham control group.

\section{Western blot analysis}

Total proteins ( $\mathrm{n}=6$ for each group) were extracted, and quantified using Bicinchoninic acid method. Then, equivalent weights of protein ( $40 \mu \mathrm{g} / \mathrm{lane})$ was separated on $10 \%$ SDSPAGE gels and then transferred to nitrocellulose membrane. The membranes were blocked with 5\% non-fat milk in TBST buffer and then incubated with the following rabbit polyclonal primary antibodies: TLR4 (1:1000 dilution; Cell Signaling Technology, Boston, MA), NF-кB (1:1000 dilution; Cell Signaling Technology, Boston, MA), $\beta$-actin (Santa Cruz Inc, 1:500). Subsequently, after being washed twice with PBS, the membranes were incubated with secondary antibody conjugated with horseradish peroxidase at 1:2000 dilution. Specific bands were visualized by using an enhanced chemiluminescence detection kit. Optical densities were detected using Quantity One software.

\section{Statistical analyses}

All data are expressed as means \pm SEM. The KolmogorovSmirnov test was applied to test for a normal distribution. The means of the different groups were compared using one-way ANOVA Student-Newman-Keuls test. All statistical analyses were performed with the SPSS statistical package (SPSS 13.0 for Windows; SPSS, Inc., Chicago, IL). Significant differences were accepted when $P$ values were less than 0.05 .

\section{Results}

\section{OzoneOP improves renal dysfunction}

The renal functional parameters of rats were significantly different at $24 \mathrm{~h}$ after $\mathrm{I} / \mathrm{R}$ injury. Rats subjected to $\mathrm{I} / \mathrm{R}$ injury showed significant increases in BUN and Cr compared with shamoperated rats. The renal function changes induced by ischemia/ reperfusion were significantly improved by OzoneOP treatment (Figure 1A, B). 
$\mathbf{A}$

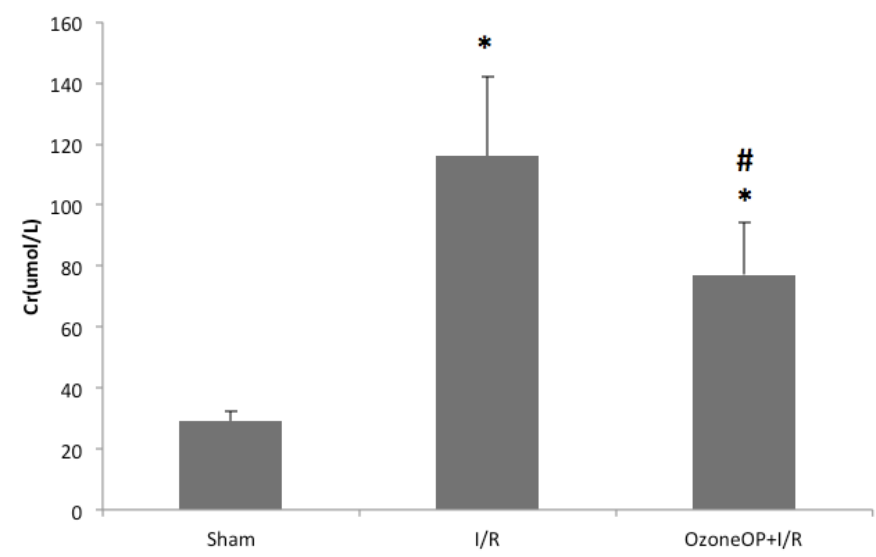

B

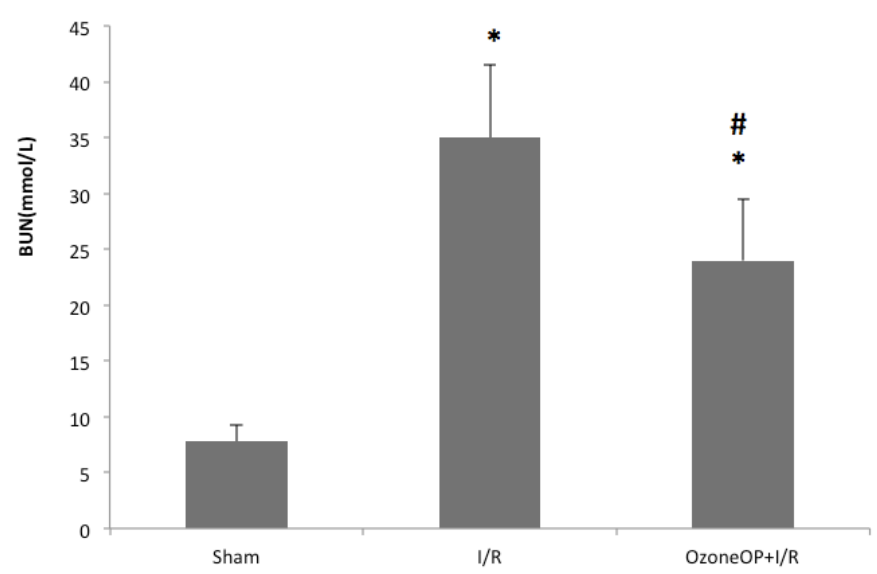

C

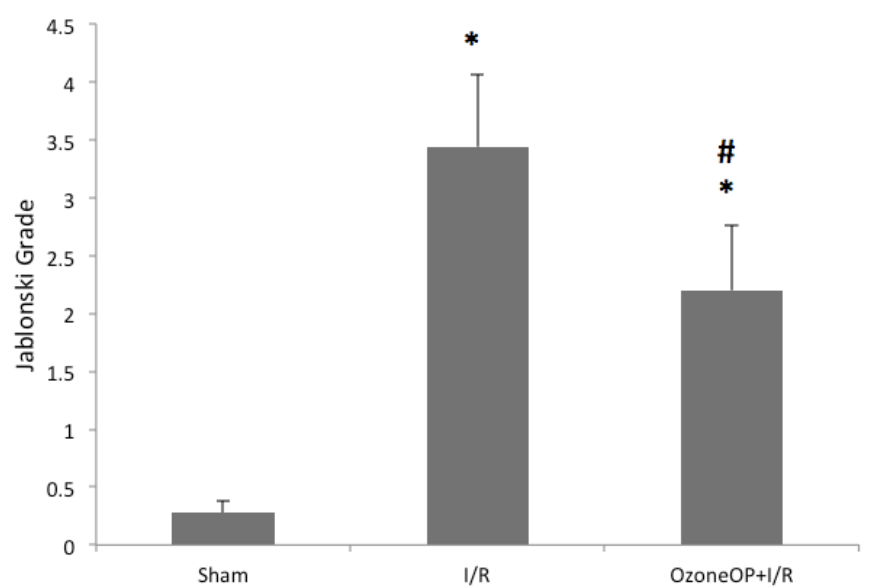

FIGURE 1 - (A) Effects of OzoneOP on the serum $\mathrm{Cr}$ concentrations after $45 \mathrm{~min}$ of ischemia. (B) Effects of OzoneOP on the serum BUN concentrations after 45 min of ischemia. (C) Jablonski scores for histological appearance of acute tubular necrosis from sham, I/R and OzoneOP $+\mathrm{I} / \mathrm{R}$ groups. Bars represent means $\pm \mathrm{SE}(\mathrm{n}=6)^{*}, \mathrm{p}<0.05$ versus sham-operated group, $\#, \mathrm{p}<0.05$ versus I/R group.
OzoneOP improves the morphological features of injury

Renal ischemia/reperfusion resulted in significant renal injury as evidenced by tubular necrosis, medullary hemorrhage, congestion and development of proteinaceous casts. OzoneOP relieved these severe renal damages (Figure 2). According to Jablonski scores, quantitative analysis showed a dramatically increased score in $\mathrm{I} / \mathrm{R}$ group. In contrast, the score was significantly reduction in OzoneOP+I/R group compared with I/R group (Figure $1 \mathrm{C}$ ).
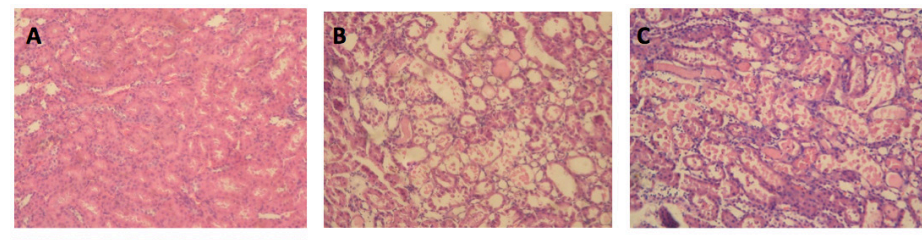

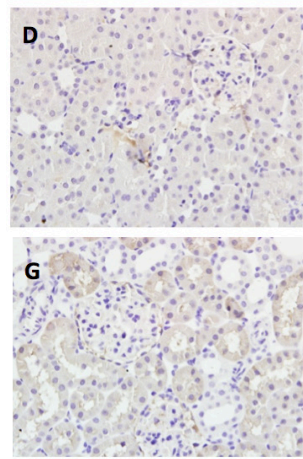

Sham

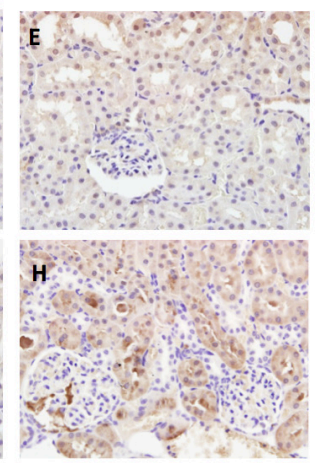

$\mathrm{I} / \mathrm{R}$

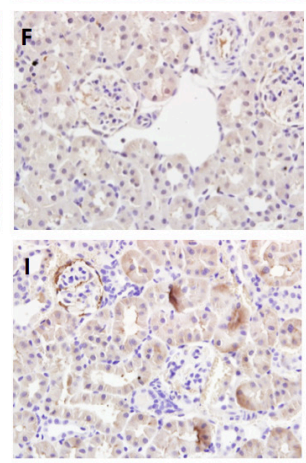

OzoneOP+I/R
FIGURE 2 - Histologic features were evaluated by HE staining and immunohistochemistry was performed for expression of TLR4 and NF- $\kappa$ B. (A, B, C) Representative kidney sections stained with HE. (D, E, F) The expression spots of TLR4 in kidneys. (G, H, I) The expression spots of NF-kB in kidneys. $(\mathbf{A}, \mathbf{D}, \mathbf{G})$ : Section from sham-operated rat. $(\mathbf{B}, \mathbf{E}, \mathbf{H})$ : Section from rat subjected to I/R treatment. (C, F, I): Section from rat treated with OzoneOP. HE staining, original magnification $\times 200$; immunohistochemical staining, original magnification $\times 400$.

\section{OzoneOP decreased TNF- $\alpha, I L-1 \beta, I L-6, I C A M-1$ and MCP-1 expression}

To investigate the mRNA expression of I TNF- $\alpha$, IL-1 $\beta$, IL-6, ICAM-1 and MCP-1, we measured their levels by realtime PCR. The mRNA levels of TNF- $\alpha$, IL-1 $\beta$, IL-6, ICAM-1 and MCP-1 were significantly greater in I/R group than in sham group. However, OzoneOP inhibited the mRNA expression of TNF- $\alpha$, IL1 $\beta$, IL-6, ICAM-1 and MCP-1after renal I/R (Figure 3). 
Xing B et al.

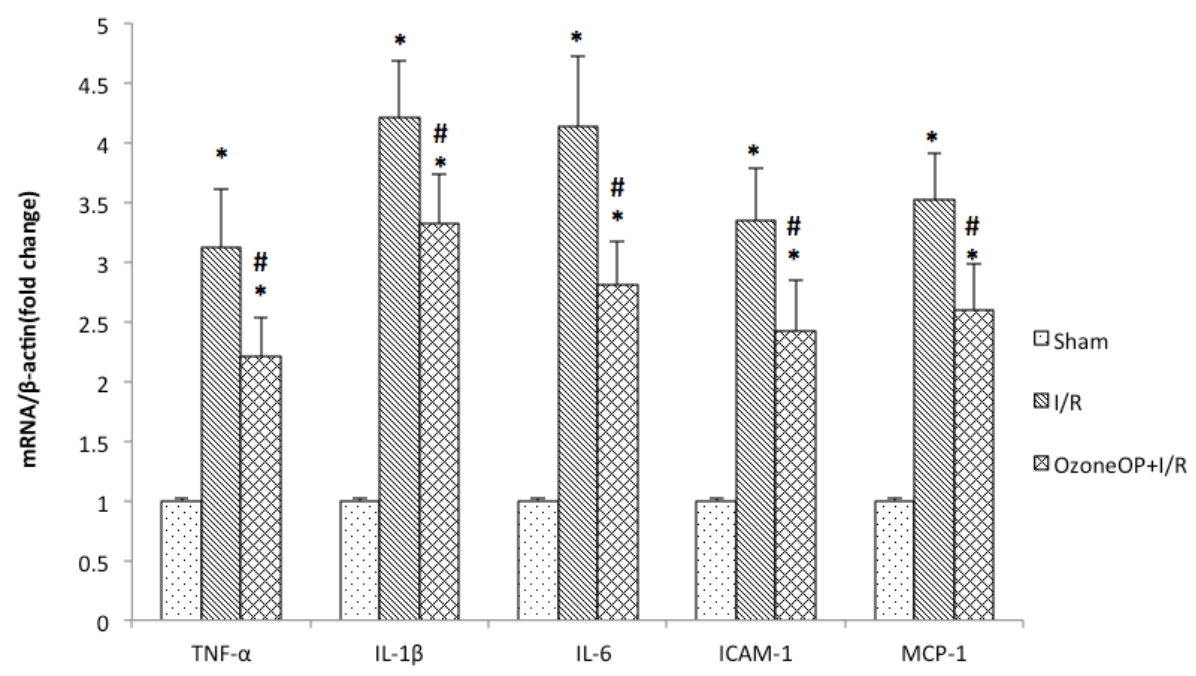

FIGURE 3 - Representative realtime PCR of TNF- $\alpha$, IL-1 $\beta$, IL-6, ICAM-1 and MCP-1 in renal tissues after 45 min of ischemia followed by 24 hours of reperfusion. Bars represent means $\pm \mathrm{SE}(n=6)^{*}, \mathrm{p}<0.05$ versus sham-operated group, \#, $\mathrm{p}<0.05$ versus I/R group.

\section{Effect of OzoneOP on TLR4 and NF- $\mathrm{BB}$ expression}

Western blot analysis and showed a significant increase of TLR4 and NF- $\kappa$ B expression in I/R group compared with sham group. Whereas the administration of OzoneOP reduced this I/Rinduced rise (Figure 4).
We localized TLR4 and NF- $\kappa$ B by immunohistochemical techniques. Stainings revealed that renal tissues were strongly positive for TLR4 and NF- $\mathrm{BB}$ expression in I/R group. Consistent with the Western blot analyses, this increase was suppressed by OzoneOP treatment (Figure 2).
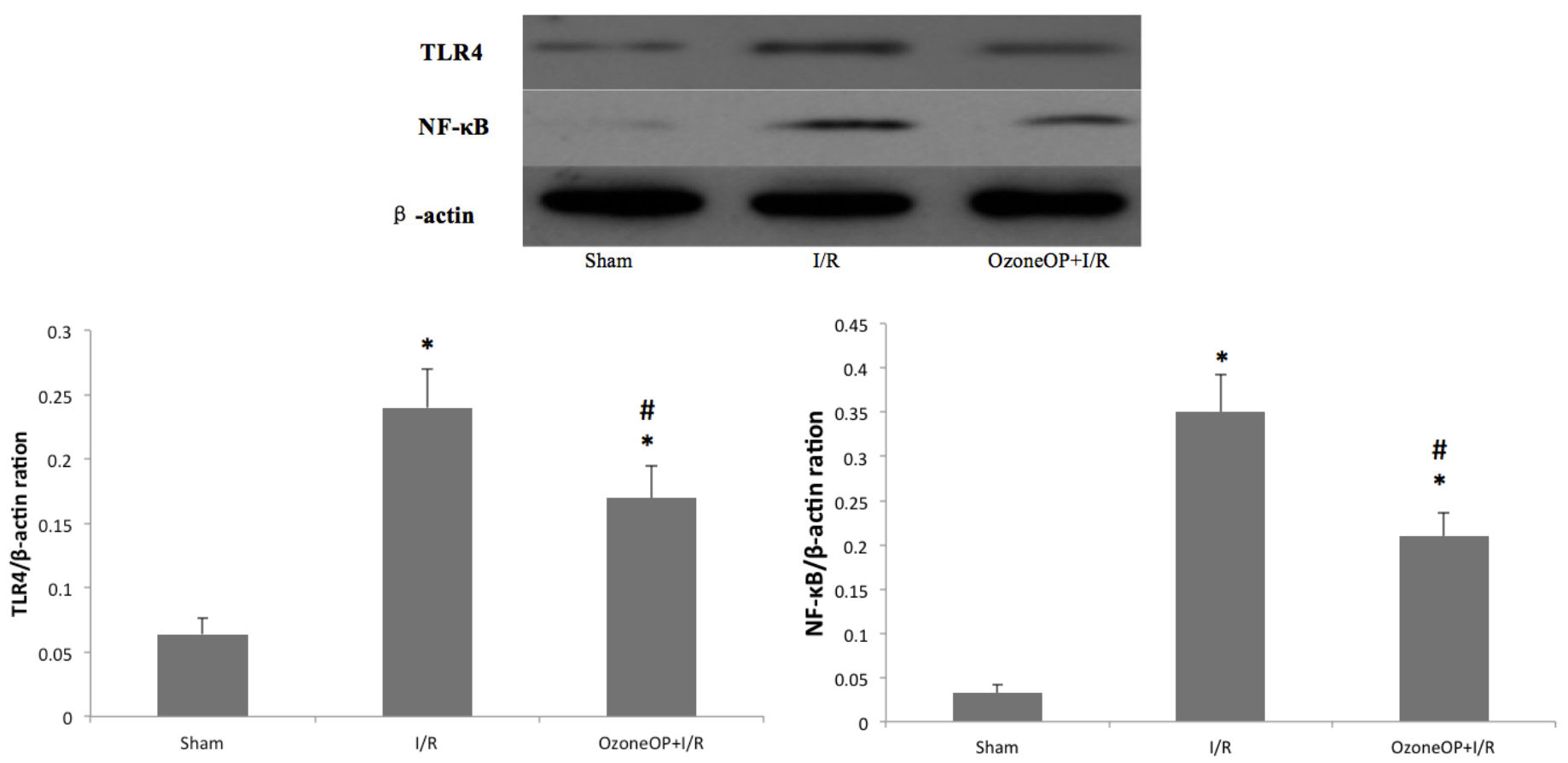

FIGURE 4 - TLR4 and NF- $\mathrm{B}$ expression after $45 \mathrm{~min}$ of ischemia followed by 24 hours of reperfusion. Bars represent means \pm SE $(\mathrm{n}=6)^{*}, \mathrm{p}<0.05$ versus sham-operated group, \#, $\mathrm{p}<0.05$ versus I/R group. 


\section{Discussion}

Our study demonstrated that OzoneOP had a renoprotective effect by attenuating inflammation in renal I/R injury. This study supported and extended our previous findings ${ }^{5}$. To further elucidate possible mechanisms mediating the anti-inflammatory effect of OzoneOP, we detected the expression of TLR4 and NF- $\mathrm{KB}$. The major findings of this study were that the tubular expression of TLR4 and NF- $\kappa \mathrm{B}$ were increased by I/R injury and suppressed by OzoneOP treatment. These results suggest that OzoneOP improved renal inflammation and damage by blocking the activation of TLR4$\mathrm{NF}-\kappa \mathrm{B}$ pathway in renal I/R injury.

Inflammation is recognized as an important component of renal I/R. Previous studies demonstrated that leukocytes infiltration into the kidney after ischemia/reperfusion injury participated in the pathogenesis of acute renal failure. The activation and expression of pro-inflammatory cytokines (TNF- $\alpha$, IL-1 $\beta$, IL-6 and ICAM-1) and chemokines responsible for macrophage (MCP-1) play a key role in the development of tissue damage. TNF- $\alpha$ play a key role in the development and maintenance of inflammatory response ${ }^{9}$. Moreover, TNF- $\alpha$ could induce renal cell apoptosis, glomerular endothelial damage and renal failure ${ }^{10}$. The expression of IL-1 $\beta$ during the early reperfusion phase can promote inflammatory and apoptotic processes ${ }^{11}$. Interleukin-6 (IL-6) is a pleiotropic cytokine and previously studies revealed that high expression level of IL-6 is a marker of inflammatory responses after I/R injury ${ }^{12}$. ICAM1 , as an adhesion molecule, could facilitate leukocytes infiltration and adhesion to aggravate the injuries caused by $I / \mathrm{R}^{13}$. In renal I/R injury, MCP-1 plays an important role in leukocyte recruitment, further compromising the outer medullary reflow and facilitating tubular cell damage ${ }^{14}$. In this study, we observed that the mRNA levels of TNF- $\alpha$, IL-1 $\beta$, IL-6, ICAM-1 and MCP-1 increased significantly in response to I/R-induced renal damage. However, OzoneOP could significantly reduce the mRNA level of TNF- $\alpha$, IL-1 $\beta$, IL-6, ICAM-1 and MCP-1. Thus, our data indicated that OzoneOP reduced inflammatory responses after renal I/R injury.

It is well known that TLR4 is a transmembrane protein that plays a central role in inflammatory cascade after renal $I / R$ injury ${ }^{1}$. The $\mathrm{I} / \mathrm{R}$ injury produces endogenous ligands and leads to the expression of TLR4 mRNA and protein expression mainly on renal tubular cells ${ }^{1}$. Furthermore, TLR4 increased expression of nuclear NF- $\kappa$ B through a MyD88-dependent pathway ${ }^{15}$. NF- $\kappa B$, an important nuclear transcription factor, regulates the expression of a large number of genes, which play a key role in the regulation of inflammation ${ }^{16}$. It is normally sequestered in an inactive form in the cytoplasm bounding to I $\kappa$ B proteins. Numerous stimuli, including
$\mathrm{I} / \mathrm{R}$ injury, could activate NF- $\kappa \mathrm{B}$ signaling by degradation of I $\mathrm{B}$ and release of the NF- $\mathrm{KB}$ p65-p50 dimer, which translocates to the nucleus and regulates transcriptional activation of the target genes $^{17}$. The activation of TLR4-NF- $\kappa B$ pathway triggers multiple down-stream effects including activation and expression of proinflammatory cytokines (TNF- $\alpha$, IL-1 $\beta$, IL-6 and ICAM-1), MCP1 accumulation and the infiltration of immune cells in ischemic kidney ${ }^{18}$. The previous study reported that OzoneOP significantly reduced $\mathrm{NF}-\kappa \mathrm{B}$ expression and inhibited inflammatory responses in liver I/R injury ${ }^{19}$. However, the role of OzoneOP on TLR4 and $\mathrm{NF}-\kappa \mathrm{B}$ expression in ischemic kidney has not been determined yet. In this study, we investigated the TLR4 and NF- $\kappa B$ expression at $24 \mathrm{~h}$ after ischemia in sham group, I/R group and OzoneOP group. Our results showed that OzoneOP significantly attenuated the TLR4 expression caused by renal ischemia/reperfusion injury, which was proved by western blot and immunohistochemistry.

There are some limitations in our study. Although OzoneOP is a simple and harmless method, a recent report showed that diabetes increases the susceptibility to I/R induced renal dysfunction in mice. This increased susceptibility derived from a heightened inflammatory response involving TNF- $\alpha$ and TLR4 signaling ${ }^{20}$. So, the aged or diseased rats may need to be investigated in further study. On one hand, only short-term period of survival were assessed. It is possible that the reduction of TLR4 might lead to long-term protection on renal fibrosis. Thus, the long-term consequences of OzoneOP may need to be investigated in further study. On the other hand, vitro studies are needed to confirm these results.

\section{Conclusions}

OzoneOP could reduce the expression of TLR4 and NF$\kappa \mathrm{B}$ expression in renal ischemia/reperfusion injury. Subsequently, decreased inflammatory molecules and leukocyte recruitment were observed. These findings suggested that the potential role of OzoneOP attenuated renal I/R injury by the modulation of TLR4$\mathrm{NF}-\kappa \mathrm{B}$ pathway.

\section{References}

1. Kim BS, Lim SW, Li C, Kim JS, Sun BK, Ahn KO, Han SW, Kim J, Yang CW. Ischemia-reperfusion injury activates innate immunity in rat kidneys. Transplantation. 2005 May 27;79(10):1370-7. PMID: 15912106.

2. Kinsey GR, Li L, Okusa MD. Inflammation in acute kidney injury. Nephron Exp Nephrol. 2008 Sep;109(4):e102-7. PMID: 18802372.

3. Bocci V, Zanardi I, Travagli V. Ozone: a new therapeutic agent in vascular diseases. Am J Cardiovasc Drugs. 2011;11(2):73-82. doi: 10.2165/11539890-000000000-00000.PMID:21446774. 
4. Barber E, Menendez S, Leon OS, Barber MO, Merino N, Calunga JL, Cruz E, Bocci V. Prevention of renal injury after induction of ozone tolerance in rats submitted to warm ischaemia. Mediators Inflamm. 1999;8:37-41. PMID: 10704088.

5. Chen H, Xing B, Liu X, Zhan B, Zhou J, Zhu H, Chen Z. Ozone oxidative preconditioning inhibits inflammation and apoptosis in a rat model of renal ischemia/reperfusion injury. Eur J Pharmacol. 2008 Mar 10;581(3):306-14. PMID: 18093583.

6. Chen H, Xing B, Liu X, Zhan B, Zhou J, Zhu H, Chen Z. Similarities between ozone oxidative preconditioning and ischemic preconditioning in renal ischemia/reperfusion injury. Arch Med Res. 2008 Feb;39(2):169-78. PMID: 18164960.

7. Chen H, Xing B, Liu X, Zhan B, Zhou J, Zhu H, Chen Z. Ozone oxidative preconditioning protects the rat kidney from reperfusion injury: the role of nitric oxide. J Surg Res. 2008 Oct;149(2):287-95. PMID: 18262565.

8. Jablonski P, Howden BO, Rae DA, Birrell CS, Marshall VC, Tange J. An experimental model for assessment of renal recovery from warm ischemia. Transplantation. 1983 Mar;35(3):198-204. PMID: 6340272 .

9. Donnahoo KK, Shames BD, Harken AH, Meldrum DR. Review article: the role of tumor necrosis factor in renal ischemia-reperfusion injury. J Urol. 1999 Jul;162(1):196-203. PMID: 10379787.

10. Donnahoo KK, Meng X, Ayala A, Cain MP, Harken AH, Meldrum DR. Early kidney TNF-alpha expression mediates neutrophil infiltration and injury after renal ischemia-reperfusion. Am J Physiol. 1999 Sep;277(3 Pt 2):R922-9. PMID: 10484513.

11. Bonventre JV, Zuk A. Ischemic acute renal failure: an inflammatory disease? Kidney Int. 2004 Aug;66(2):480-5. PMID: 15253693.

12. Kielar ML, John R, Bennett M, Richardson JA, Shelton JM, Chen L, Jeyarajah DR, Zhou XJ, Zhou H, Chiquett B, Nagami GT, Lu CY. Maladaptive role of IL-6 in ischemic acute renal failure. J Am Soc Nephrol. 2005 Nov;16(11):3315-25. PMID: 16192425.

13. Carden DL, Granger DN. Pathophysiology of ischaemia-reperfusion injury. J Pathol. 2000 Feb;190(3):255-66. PMID: 10685060.

14. Rice JC, Spence JS, Yetman DL, Safirstein RL. Monocyte chemoattractant protein-1 expression correlates with monocyte infiltration in the post-ischemic kidney. Ren Fail. Nov;24(6):70323. PMID: 12472194 .

15. Lotze MT, Tracey KJ. High-mobility group box 1 protein (HMGB1): nuclear weapon in the immune arsenal. Nat Rev Immunol. 2005 Apr;5(4):331-42. PMID: 15803152.
16. Chen F, Castranova V, Shi X. New insights into the role of nuclear factor-kappaB in cell growth regulation. Am J Pathol. 2001 Aug;159(2):387-97. PMID: 11485895.

17. Wong ET, Tergaonkar V. Roles of NF-kappaB in health and disease: mechanisms and therapeutic potential. Clin Sci (Lond) . 2009 Mar;116(6):451-65. PMID: 19200055.

18. Wu H, Chen G, Wyburn KR, Yin J, Bertolino P, Eris JM, Alexander SI, Sharland AF, Chadban SJ. TLR4 activation mediates kidney ischemia/reperfusion injury. J Clin Invest. 2007 Oct;117(10):284759. PMID: 17853945.

19. Leon FO, Ajamieh HH, Berlanga J, Menendez S, Viebahn-Hansler $\mathrm{R}$, Re L, Carmona AM. Ozone oxidative preconditioning is mediated by $\mathrm{A} 1$ adenosine receptors in a rat model of liver ischemia/ reperfusion. Transpl Int. 2008 Jan;21(1):39-48. PMID: 17927680.

20. Gao G, Zhang B, Ramesh G, Betterly D, Tadagavadi RK, Wang W, Reeves WB. TNF-alpha mediates increased susceptibility to ischemic AKI in diabetes. Am J Physiol Renal Physiol. 2013 Mar 1;304(5):F515-21. PMID: 23283990.

\section{Correspondence:}

Hui Chen

Department of Urology

Renmin Hospital of Wuhan University

Jiefang Road 238, Wuhan, Hubei, China, 430060

Phone: (86)027-88041911(82235)

drchenhuiyx@163.com

Received: Sep 29, 2014

Review: Nov 28, 2014

Accepted: Dec 30, 2014

Conflict of interest: none

Financial source: National Natural Science Foundation of China (nos. 30901494 and 30901552).

${ }^{1}$ Research performed at Key Laboratory, Hubei Province, Digestive System Disease, Department of Gastroenterology, Renmin Hospital, Wuhan University, Hubei, China. 